\title{
MODELING OF WEDM PROCESS FOR COMPLEX SHAPE USING MULTILAYER PERCEPTRON AND RESPONSE SURFACE METHODOLOGY
}

\author{
V. L. Bhambere ${ }^{1}$, S. S. Khandare ${ }^{2}$ \\ ${ }^{1}$ Research Scholar, BDCOE Sevagram, Wardha, M.S. India, \\ vijaylbhambere@gmail.com,+918308751751 \\ ${ }^{2}$ Ex. princIpal, B.D.C.O.E Sewagram, Wardha, M.S. India, \\ shashikhan_ngp@hotmail.com
}

\begin{abstract}
Wire cut electric discharge machining is the present days requirement in manufacturing the intricate and complex shape parts as required in the modern industrial products. The process being complex in nature for control over the machining process parameters. In the present study Multilayer perceptron (MLP) model is developed to predict the Material removal rate. The mathematical regression model is also developed by using Response Surface Methodology (RSM) to establish the relationshIp between the MRR and input process parameters like pulse on time $\left(T_{o n}\right)$, Pulse off time $\left(T_{\text {off }}\right)$, Peak current $\left(I_{P}\right)$ and Servo voltage (SV). The predicted value by using MLP and RSM were compared with the experimental values. The average percentage errors are found to be 1.29 and -0.36527 for MLP and RSM respectively. It is observed that the predicted values with RSM are closer to experimental values as compared to MLP model.
\end{abstract}

Key Words: WEDM, Response Surface Methodology, Neural Network, Multi Layer Perception, Material Removal Rate, Surface Roughness

\section{INTRODUCTION}

Wire electric discharge machining (WEDM) process has created revolution in manufacturing industry. As machining of hard and composite materials, super alloys becomes easier to cut intricate shapes and complex profiles. Producing the parts of high quality at high production rate efficiency by optimizing the machining conditions is the prime objective of WEDM. Optimal machining conditions can be obtained by carrying out the analysis of the input variables, response variables and interaction between them. The most Significant performance parameters in WEDM are cutting rate, workpiece surface roughness, dimensional deviation and kerf. Machining parameters includes pulse on, pulse off, peak current, servo voltage, wire tension, water pressure and wire speed. During the research work on WEDM machine many researchers have focused on various aspects related to WEDM which includes state of the art in wire electric discharge machines, optimization of process parameters on machining different workpiece materials including different types of alloys of materials, composites and many more newly investigated tougher materials required in aerospace industries, tools and die making industries etc. some have concentrated on wire breakage phenomenon during the machining process and its effects on obtainable surface finish and various methods to overcome it. As well some have suggested the selection of optimum process parameters on machine setting to get the desired surface finish on machining. Puri A. B., et al. [8] in this paper an analytical approach in the solution of the wire-tool equation by considering multIple spark discharges to investigate wire vibration effects in WEDM. Portillo E., et al.[4] developed recurrent neural network model to diagnose degraded cutting regimes in Wire Electrical Discharge Machining process, which helps to detect the degradation of the cutting process which results in breakage of the wire electrode tool, productivity of the process and accuracy required. In 2010 Reddy V. B., et al. [9] developed to predict WEDM for chromium molybdenum -vanedium alloyed special steel an artificial neural network model. The steel being used in automobile industry. Similarly in 2014 Varun A., et al.[10] proposed to couple grey relational analysis (GRA) and genetic algorithm (GA) for optimizing they conducted the experiments with EN 353 work material for studying various process parameters effects on the response parameter. Spedding, T.A. and wang Z.Q. [1] described the parametric combinationwith the use of artificial neural network and they also characterised the surface roughness and waviness along with cutting speed. Trang Y. S. et al.[2] developed a neural network model to determine pulse duration, time, open circuit voltage, peak current, electric capacitance and wire speed servo reference voltage for the estimation of cutting speed and surface. Ramakrishnana R. and Karunamoorthyb L[3] developed artificial neural network model with Taguchi parameter design for modeling of CNC WEDM process. Caydas et al. 
[12] proposed adaptive neuro-fuzzy inference system (ANFIS) model for the prediction of the white layer thickness (WLT) and the average surface roughness obtained as a function of the process parameters. Tomura Shunsuke, et al.[11] clarify the mechanism that how electromagnetic force is applied to the wire electrode in wire electrical discharge machining (wire-EDM) is being generated Poros Dariusz, et al.[7] experimentally investigated the efficiency of wire electrical discharge machining of difficult-to-machine materials with Uncoated brass wire, $0.25 \mathrm{~mm}$ diameter, brass $\mathrm{CuZn} 20$ coated brass $\mathrm{CuZn50}$ wire and zinc oxide coated brass wire were utilized in the experimentation. Okada A., et al.[6] proposed high-speed observation system for fine wire EDM process. Nithin Aravind S. R., et.al [5] attempted to determine the important machining parameters of brass material for the performance measures like Material removal rate and Surface roughness separately in WEDM process.

The objective of this paper is to develop the neural network and mathematical regression model to predict the surface roughness for the given set of input conditions. The Artificial neural network model is designed with the help MLP to predict material removal rate. Experiments are carried out on High carbon High Chromium tool steel (HCHCR). The predicted values with ANN model and the regression model are also compared with the experimental values.

\section{MATERIAL}

The material used in this experiment is High carbon High Chromium tool steel (HCHCR) having size $220 \mathrm{~mm} \mathrm{X}$ $220 \mathrm{~mm}$ X40mm. The chemical composition of the HCHCR workpiece material is given in table 1 .

Table 1: Chemical Composition of the HCHCR Material

\begin{tabular}{|c|c|c|c|c|c|c|c|c|c|c|c|c|c|}
\hline Constituent & $\mathbf{C}$ & $\mathbf{S i}$ & $\mathbf{M n}$ & $\mathbf{P}$ & $\mathbf{S}$ & $\mathbf{C r}$ & $\mathbf{N i}$ & $\mathbf{M o}$ & $\mathbf{A l}$ & $\mathbf{C u}$ & $\mathbf{V}$ & $\mathbf{N b}$ & $\mathbf{T i}$ \\
\hline $\begin{array}{c}\boldsymbol{\%} \\
\text { Composition }\end{array}$ & 2.012 & 0.184 & 0.290 & 0.021 & 0.021 & 11.337 & 0.097 & 0.048 & $<0.001$ & 0.036 & 0.051 & 0.004 & 0.001 \\
\hline
\end{tabular}

\section{EXPERIMENTAL PROCEDURE}

The experiments were conducted on Electronica Sprintcut 734 DLX model. The Brass wire with $0.25 \mathrm{~mm}$ diameter is used in the experiment. Four input factors like pulse on (Ton), pulse off (Toff), peak current $\left(\mathrm{I}_{\mathrm{P}}\right)$ and servo voltage (SV) were selected as a control variable and the effects of these input parameters are studied on Material Removal Rate (MRR). The various input parameter values and their level are given in Table 2 . The thirty number of experiments were conducted according to Central Composite Rotatable Design of experiments (CCD). The prime objective of employing the CCD is to reduce the number of experiments to be performed. Four process parameters are examined at three levels as presented in table 2. Program was developed for the complex shape punch having hexagon on top face and circle at bottom face by using Auto CAD Software. The top view of machined 30 punches is shown in figure 1 . Minitab 14 software has been used for the design of experiments. The experimental results obtained with CCD experiments is shown in table 3. The MRR (grams per min) is calculated as:

$$
M R R=\frac{\left(W_{i-} W_{f}\right)}{t}
$$

Where,

$$
\mathrm{Wi}=\text { Initial weight of work piece material }
$$

$$
\mathrm{W}_{\mathbf{f}}=\text { Final weight of work piece material }
$$

$\mathrm{t}=$ Time period of each trial in minutes

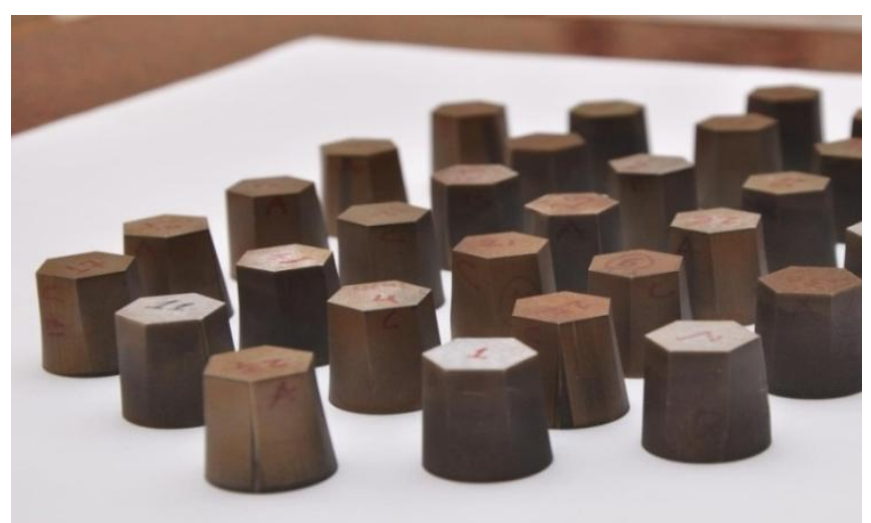

Figure 1: Top view for machined punches

Table 2: Process parameters, symbols, levels and their ranges

\begin{tabular}{|c|c|c|c|c|c|c|}
\hline Process & Symbols & Units & $\begin{array}{c}\text { Range } \\
\text { (Machine } \\
\text { Parameters }\end{array}$ & & \multicolumn{3}{|c|}{ Levels } \\
\cline { 5 - 7 } & & Units) & $\mathbf{- 1}$ & $\mathbf{0}$ & $\mathbf{1}$ \\
\hline $\begin{array}{c}\text { Pulse On } \\
\text { time }\end{array}$ & Ton & $\mu \mathrm{s}$ & $120-130$ & 120 & 125 & 130 \\
\hline $\begin{array}{c}\text { Pulse Off } \\
\text { Time }\end{array}$ & Toff & $\mu \mathrm{s}$ & $40-58$ & 40 & 49 & 58 \\
\hline $\begin{array}{c}\text { Peak } \\
\text { Current }\end{array}$ & $\mathrm{IP}$ & Amp & $180-230$ & 180 & 210 & 230 \\
\hline $\begin{array}{c}\text { Servo } \\
\text { Voltage }\end{array}$ & SV & V & $7-20$ & 7 & 13 & 20 \\
\hline
\end{tabular}

\section{RESPONSE SURFACE METHODOLOGY}

RSM is useful for the modeling and analysis of experiments in which a response of interest is influenced by several variables and the objective is to optimize that response. The initial requirement of RSM for achieving the accurate and reliable measurements of response variables is design of experiments. For modeling the input output parameters we 
have developed response surface regression equation as given below.

$\operatorname{MRR}=-4.65868+0.0788175^{*} T_{\text {on }}+0.00178855^{*} T_{\text {off }}-$ $0.00297111 * I_{P^{-}} 0.0089671 * S V-0.000301186 * T_{o n}{ }^{2}$ $+0.000011979 * T_{\text {off }}^{2}+0.00000727378 * I_{P}{ }^{2}-0.0000740702 *$ $S V^{2}-0.0000444444 * T_{\text {on }} * \quad T_{\text {off }} \quad-0.0000021034 * T_{\text {on }} * I_{P}$ $+0.0000463068 * \quad T_{\text {on }} * S V+0.00000673545 * T_{\text {off }}$ $* I_{P}+0.0000554538 * T_{\text {off }} * S V+0.00000773324 * I_{P} * S V$

Table 3: MRR obtained from the Experiments

\begin{tabular}{|c|c|c|c|c|c|}
\hline \multirow{2}{*}{$\begin{array}{c}\text { Expt. } \\
\text { No. }\end{array}$} & \multicolumn{4}{|c|}{ Input Parameter } & \multirow{2}{*}{$\begin{array}{c}\text { Output } \\
\text { Actual MRR }\end{array}$} \\
\hline & $T_{\text {on }}$ & $T_{o f f}$ & $I_{P}$ & $S V$ & \\
\hline 1 & 130 & 40 & 230 & 20 & 0.048 \\
\hline 2 & 130 & 58 & 230 & 20 & 0.047 \\
\hline 3 & 130 & 58 & 230 & 7 & 0.045 \\
\hline 4 & 125 & 49 & 210 & 13 & 0.041 \\
\hline 5 & 120 & 58 & 180 & 7 & 0.027 \\
\hline 6 & 120 & 58 & 180 & 20 & 0.018 \\
\hline 7 & 130 & 58 & 180 & 7 & 0.037 \\
\hline 8 & 125 & 49 & 210 & 13 & 0.050 \\
\hline 9 & 130 & 58 & 180 & 20 & 0.031 \\
\hline 10 & 130 & 40 & 180 & 7 & 0.058 \\
\hline 11 & 130 & 40 & 230 & 7 & 0.062 \\
\hline 12 & 125 & 49 & 210 & 13 & 0.043 \\
\hline 13 & 120 & 58 & 230 & 20 & 0.031 \\
\hline 14 & 120 & 40 & 230 & 7 & 0.045 \\
\hline 15 & 120 & 58 & 230 & 7 & 0.038 \\
\hline 16 & 125 & 49 & 210 & 13 & 0.046 \\
\hline 17 & 120 & 40 & 180 & 20 & 0.017 \\
\hline 18 & 120 & 40 & 180 & 7 & 0.042 \\
\hline 19 & 130 & 40 & 180 & 20 & 0.042 \\
\hline 20 & 120 & 40 & 230 & 20 & 0.028 \\
\hline 21 & 120 & 49 & 210 & 13 & 0.031 \\
\hline 22 & 125 & 49 & 210 & 13 & 0.046 \\
\hline 23 & 125 & 49 & 210 & 13 & 0.043 \\
\hline 24 & 125 & 49 & 210 & 7 & 0.047 \\
\hline 25 & 125 & 40 & 210 & 13 & 0.050 \\
\hline 26 & 130 & 49 & 210 & 13 & 0.045 \\
\hline 27 & 125 & 49 & 180 & 13 & 0.044 \\
\hline 28 & 125 & 49 & 210 & 20 & 0.037 \\
\hline 29 & 125 & 49 & 230 & 13 & 0.054 \\
\hline 30 & 125 & 58 & 210 & 13 & 0.043 \\
\hline
\end{tabular}

\section{MODELING WITH ARTIFICIAL NEURAL NETWORK}

The Multilayer perceptron is the most common model of neural network. This type of neural network is called as supervised network because it requires a desired output in order to learn. The objective of this type of network is to create a model that correctly maps the input to the output using historical data so that the (2) model can then be used to produce the output when the desired output is not known. The graphical representation of an Multilayer perceptron is given in figure.

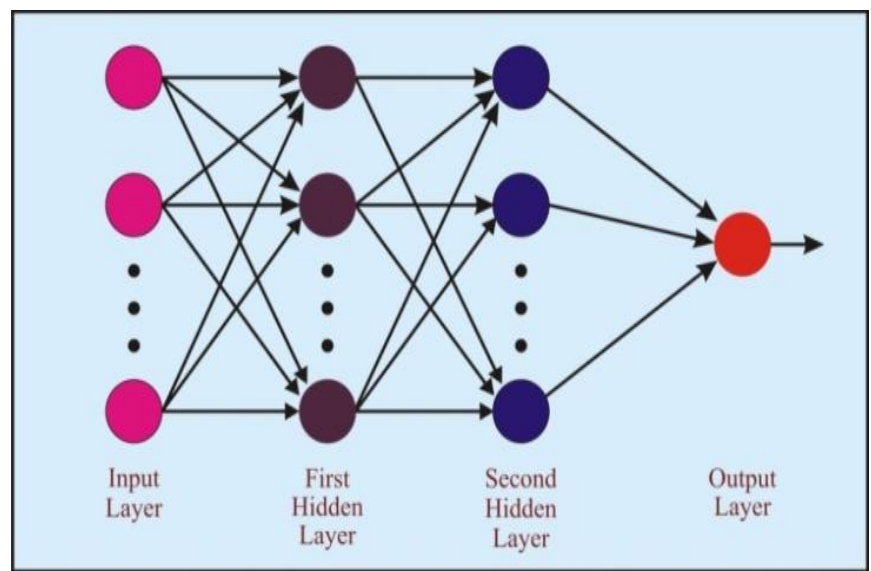

Figure 1: Architecture of Multilayer Perceptron (MLP)

The Multilayer Perceptron and many other neural networks learn using algorithm called back propagation. With back propagation, the input data is repeatedly presented to the neural network. With each presentation the of the neural network output is compared to the desired output and an error is computed. To analyze the validity of Response Surface Methodology we have also used Artificial Neural Network. For prediction of MRR single hidden layer multilayer perceptron was used. With the different random initialization of weights $60 \%$ of data is used for training, $10 \%$ data is used for cross validation and $30 \%$ data is used for testing purpose. Five number of processing elements are used in the hidden layer. MLP was trained with momentum and tanh as a learning rule and transfer function respectively. The network is trained three times with different random initialization of weights to ensure the true learning. The results obtained with RSM and MLP are given in table 4 . Table 4 also shows the comparison between experimental values obtained at different conditions, predicted values through ANN (MLP) and predicted values by RSM model. Figure 2 shows graphical comparison between MRR values by Experiment, RSM and ANN, it represents that both the curves for ANN and RSM model exhibits nearly the same pattern as that of actual values which proves the model adequacy. 
Table 4: Comparison between MRR values by Experiment, RSM and ANN

\begin{tabular}{|c|c|c|c|c|}
\hline $\begin{array}{c}\text { Actual } \\
\text { MRR(HCHCR) }\end{array}$ & $\begin{array}{c}\text { Predicted } \\
\text { MRR ANN } \\
\text { Output } \\
\end{array}$ & $\begin{array}{c}\text { Predicted } \\
\text { MRR RSM }\end{array}$ & $\begin{array}{c}\text { ANN } \\
\text { (MLP) } \\
\text { \%Error } \\
\end{array}$ & $\begin{array}{c}\text { RSM \% } \\
\text { Error }\end{array}$ \\
\hline 0.048115 & 0.04817 & 0.04901 & -0.11229 & -1.87091 \\
\hline 0.047317 & 0.04742 & 0.04619 & -0.22039 & 2.38712 \\
\hline 0.045 & 0.04520 & 0.04557 & -0.43980 & -1.25732 \\
\hline 0.0412 & 0.04450 & 0.04518 & -7.99922 & -9.66786 \\
\hline 0.026776 & 0.02674 & 0.02755 & 0.13492 & -2.90350 \\
\hline 0.01837 & 0.01815 & 0.01713 & 1.19099 & 6.75500 \\
\hline 0.036741 & 0.03656 & 0.03644 & 0.48224 & 0.81627 \\
\hline 0.0496 & 0.04450 & 0.04518 & 10.29097 & 8.90492 \\
\hline 0.031315 & 0.03129 & 0.03204 & 0.08175 & -2.30484 \\
\hline 0.058193 & 0.05853 & 0.05831 & -0.57397 & -0.19571 \\
\hline 0.061823 & 0.06094 & 0.06137 & 1.42618 & 0.73378 \\
\hline 0.0425 & 0.04450 & 0.04518 & -4.69572 & -6.31332 \\
\hline 0.0314 & 0.03140 & 0.03233 & 0.01559 & -2.96850 \\
\hline 0.044505 & 0.04456 & 0.04553 & -0.11485 & -2.30948 \\
\hline 0.038303 & 0.03819 & 0.03773 & 0.30336 & 1.49541 \\
\hline 0.04555 & 0.04450 & 0.04518 & 2.31541 & 0.80613 \\
\hline 0.0165 & 0.01708 & 0.01802 & -3.54145 & -9.20179 \\
\hline 0.0416 & 0.04147 & 0.04142 & 0.32418 & 0.43541 \\
\hline 0.042 & 0.04205 & 0.04093 & -0.11615 & 2.55768 \\
\hline 0.027817 & 0.02765 & 0.02716 & 0.61060 & 2.36683 \\
\hline 0.030878 & 0.03125 & 0.03014 & -1.20732 & 2.40381 \\
\hline 0.04555 & 0.04450 & 0.04518 & 2.31541 & 0.80613 \\
\hline 0.0431 & 0.04450 & 0.04518 & -3.23824 & -4.83332 \\
\hline 0.047126 & 0.04757 & 0.04710 & -0.93603 & 0.06291 \\
\hline 0.049812 & 0.04752 & 0.05027 & 4.59677 & -0.92607 \\
\hline 0.045 & 0.05004 & 0.04517 & -11.20639 & -0.38001 \\
\hline 0.043882 & 0.03507 & 0.04418 & 20.07696 & -0.68792 \\
\hline 0.036582 & 0.03341 & 0.03621 & 8.66567 & 1.01586 \\
\hline 0.053825 & 0.04823 & 0.05312 & 10.38640 & 1.30377 \\
\hline 0.042897 & 0.03870 & 0.04203 & 9.77729 & 2.01097 \\
\hline \multicolumn{3}{|c|}{ Average $\%$ Error } & 1.28643 & -0.36529 \\
\hline
\end{tabular}

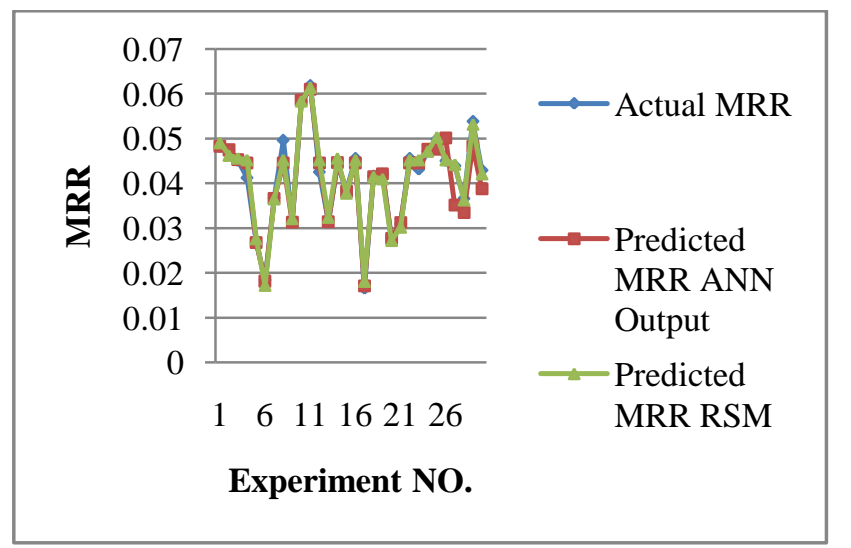

Figure 2: Comparison between MRR (HCHCR) values by Experiment, RSM and ANN

\section{RESULT AND CONCLUSION:}

This paper presents the modeling of WEDM process for the complex shape. Two models were developed for predicting the material removal rate for manufacturing the complex shape punches. We have used response surface methodology for developing mathematical regression equation. The Artificial Neural Network with MLP was aslo designed for predicting the MRR. The values predicted by RSM and ANN model are compared with experimental values and the average percentage error is also calculated. IT is observed that values predicted with both the models are approximately same as the experimental values. the average percentage error is $1.28643 \%$ and $-0.36829 \%$ for ANN and RSM model respectively.

\section{REFERENCES}

[1]. Spedding T. A. \& Wang Z. Q. (1997), Parametricoptimization and suface characterization of wire electrical discharge machining process. Précis. Eng. Vol. 20, pp. 5-15.

[2]. Tarng Y. S., Ma S. C. \& Chung L. K. (1995), Determination of optimal cutting parameters in wire electrical discharge machining. International journal of Machine Tools Manufacture. Vol. 35, pp. 1693-1701.

[3]. Ramakrishnana R. \& Karunamoorthyb L. (2008), Modeling and multi response optimization of inconel 718 on machining of CNC WEDM process. Journal of Materials processing Technology, Vol. 207, pp. 343349.

[4]. Portillo E., Marcos M., Cabanes I., Zubizarreta A., Sanchez J.A. (2008), "Artificial Neural Networks for Detecting Instability Trends in Different Workpiece Thicknesses in a Machining Process", 2008 American Control Conference Westin Seattle Hotel, Seattle, Washington, USA June 11-13.

[5]. Nithin Aravind S. R., Sowmyi S., Yuvara K. P. (2012), "Optimization of Metal Removal Rate And Surface Roughness on Wire Edm Using Taguchi Method", IEEE-International Conference On Advances In Engineering, Science And Management (ICAESM 2012) March 30, 31, 2012.

[6]. Okada A., Uno Y., Nakazawa M., Yamauchi T. (2010), "Evaluations of spark distribution and wire vibration in wire EDM by high-speed Observation”, CIRP Annals Manufacturing Technology 59, 231-234.

[7]. Poros Dariusz, Zaborski Stanisław (2009), "Semiempirical model of efficiency of wire electrical discharge machining of hard-to-machine materials", journal of materials processing technology 209, 12471253.

[8]. Puri A. B., Bhattacharyya B. (2003), “An analysis and optimisation of the geometrical inaccuracy due to wire lag phenomenon in WEDM", International Journal of Machine Tools \& Manufacture 43, 151-159.

[9]. Reddy Vijaya Bhaskara., Vikaram kumar C. H. R., Reddy Hemachandra.K (2010), "Modeling Of Wire EDM Process Using Back Propagation (BPN) and General Regression Neural Networks (GRNN)", IEEE 2010 
[10]. Varun A., Venkaiah Nasina (2015), "Simultaneous optimization of WEDM responses using grey relational analysis coupled with genetic algorithm while machining EN 353", International Journal of Advance Manufacturing Technology, 76:675-690.

[11]. Tomura Shunsuke, Kunieda Masanori (2009), "Analysis of electromagnetic force in wire-EDM", Precision Engineering 33, 255-262.

[12]. Caydas Ulas, Hascalık Ahmet, Ekici Sami (2009), “An adaptive neuro-fuzzy inference system (ANFIS) model for wire-EDM", Expert Systems with Applications 36, 6135-6139. 